\title{
Interactive effects of predation risk and parasitism on the circadian rhythm of foraging activity in the great pond snail Lymnaea stagnalis (Gastropoda: Lymnaeidae)
}

\author{
Ari Voutilainen* \\ Ecological Research Institute, Faculty of Science and Forestry, University of Eastern Finland, Joensuu campus, P.O. Box 111, \\ 80101 Joensuu, Finland
}

Received 13 April 2010; Accepted 22 August 2010

\begin{abstract}
Four experiments were serially carried out conducted to study foraging activity in the freshwater gastropod Lymnaea stagnalis in the absence and presence of predators (crayfish or fish) under daylight and in the dark. The snails were either parasitized by digenean trematodes (Diplostomum pseudospathaceum or Plagiorchis elegans) or remained unparasitized. The snails had an evident circadian foraging rhythm: they preferred diurnal foraging notwithstanding the predators and parasites. However, the snail's parasite status and the predation risk had an interaction effect on the number of feeding events per snail individual so that especially the snails parasitized by $D$. pseudospathaceum were more active in the presence of a fish predator than in the absence of predators. Some of the snails responded to cues from a crayfish predator by crawling out of the water. The results suggest that D. pseudospathaceum may be capable of manipulating the behaviour of its first intermediate snail host in ways that enhance its success of transmission to the parasite's second intermediate fish host. The results also indicate that the effects of biotic stressors, such as predation risk and parasitism, on the foraging pattern in the snails L. stagnalis may be interactive and highly specialized rather than generalized.
\end{abstract}

Key words: Anti-predator behaviour / biological rhythms / biotic stressors / digenean trematodes / parasitemediated behaviour

\section{Introduction}

Behaviour of snails (Mollusca: Gastropoda) is affected by several biotic and abiotic factors including e.g. predation, parasitism and light conditions. Generally, snails try to minimize their predation risk by populating habitats that provide a refuge from the predators (Alexander and Covich, 1991a; Turner, 1996) and by being less active during times when the predation risk is high (Sih and McCarthy, 2002). The type and degree of the avoidance response by snails depend on the type of the predator (Turner et al., 1999), the strength of the cues from the predator (stronger cues eliciting greater responses: McCarthy and Fisher, 2000; Keppel and Scrosati, 2004) and snail body size (Alexander and Covich, 1991b).

Parasitism may alter the reproduction, phenotype and behavioural traits of the infected snails. Many trematode parasites reduce the reproductive output of their snail hosts (parasitic castration) (Zakikhani and Rau, 1998,

\footnotetext{
*Corresponding author: ari.voutilainen@uef.fi
}

1999), affect the growth of the parasitized individuals (gigantism) (Ballabeni, 1995), cause deformation of shells of the snails (Żbikowska and Żbikowski, 2005) and alter the biological rhythms, foraging behaviour and responses to abiotic stimuli such as light and gravity of the infected hosts (Levri, 1999; Levri and Fisher, 2000; Levri et al., 2007). Some trophically transmitted parasites are even able to alter the behaviour of their snail hosts to enhance the success of transmission to their next intermediate or definitive hosts (e.g., Levri et al., 2007). However, in many cases there have been difficulties to state, whether the altered behaviour of the infected snails was a specific response to the parasitism or a by-product of the infection. In general, a specific response to parasitism refers to adaptations of the host or the parasite to enhance its survival and a by-product of infection refers to changes in the host's behaviour or energy allocation that e.g., generate increased growth without any evident benefits for the host or the parasite.

In this study, I examined the effects of predation risk and parasitism on the circadian rhythm of foraging 
activity in the great pond snail Lymnaea stagnalis (L.) (Gastropoda: Lymnaeidae) under two different light conditions (bright diffuse daylight and darkness) with special emphasis on the possible interactions between the effects of the two biotic stressors (parasitism and predation risk). All the snails were adults and either parasitized by the trematodes Diplostomum pseudospathaceum (Digenea: Diplostomidae) and Plagiorchis elegans (Digenea: Plagiorchiidae) or remained unparasitized. Both D. pseudospathaceum and $P$. elegans are trophically transmitted parasites, and they use lymnaeid snails, especially L. stagnalis, as the first intermediate hosts (Bock, 1984; Niewiadomska, 1996). The second intermediate hosts of D. pseudospathaceum are fish (Niewiadomska, 1996) and those of P. elegans are mosquito larvae (Diptera: Culicidae) (Bock, 1984). The final hosts of D. pseudospathaceum are fish-eating birds, such as gulls (Niewiadomska, 1996). Final host specificity of Plagiorchis species is low and under laboratory conditions they can infect birds and mammals (Bock, 1984; Zakikhani et al., 2003). Diplostomum species manipulate the behaviour of their fish hosts by causing cataract in the eye lens of the fish. The cataract-bearing fish are more vulnerable to avian predation (Seppälä et al., 2004, 2005), which in turn enhances the parasites' success of transmission to their final hosts.

Experimental snails were stressed by predation risk caused by the presence of a facultative crustacean molluscivore (the crayfish Astacus astacus L.) or an efficient fish molluscivore (the crucian carp Carassius carassius (L.)). The following hypotheses were stated: (1) the presence of the fish stimulates the snails infected with D. pseudospathaceum to forage more actively, (2) the presence of a nocturnal predator (crayfish) decreases the foraging activity in the snails during the dark periods and (3) the presence of a diurnal predator (fish) decreases the foraging activity in the snails during the illuminated periods. The first hypothesis was based on the presumption that the trematode parasite $D$. pseudospathaceum is capable of manipulating the behaviour of its first intermediate snail host to enhance its success of transmission to the parasite's second intermediate fish host. As the cercariae of $D$. pseudospathaceum are highly infectious to fish only during the first hours after emerging from the snail into the water and they are not able to actively swim towards the fish (Karvonen et al., 2003), the cercariae have a serious need of being released from the snail host in close vicinity to their next host i.e. the fish. Consequently, if the snails parasitized by $D$. pseudospathaceum became especially active in the presence of fish ("seek the fish"), the parasite gets benefit from the snail's behaviour. The cercariae of $D$. pseudospathaceum infect the fish by penetrating its skin (Niewiadomska, 1996) so they have no need of being eaten by the fish.

\section{Materials and methods}

The snails L. stagnalis were obtained from Lake Huumonjärvi situated in Northern Finland $\left(65^{\circ} 6^{\prime} \mathrm{N}\right.$, $26^{\circ} 8^{\prime} \mathrm{E}$ ) in August 2008. Lake Huumonjärvi is small (area $47 \mathrm{ha}$ ) and eu-mesotrophic (total phosphorus $21 \mu \mathrm{g} . \mathrm{L}^{-1}$, total nitrogen $704 \mu \mathrm{g} . \mathrm{L}^{-1}$ and chlorophyll $a 20 \mu \mathrm{g} . \mathrm{L}^{-1}$ in August 2007). Water of the lake is slightly humic and brown (water colour $70 \mathrm{mg}$ Pt.L ${ }^{-1}$ in August 2007). The habitat of L. stagnalis is partly open and partly vegetated by the common reed Phragmites australis with a sandy bottom. Both diurnal (fish, such as large roach Rutilus rutilus (L.)) and nocturnal (crayfish) predators of snails are present in Lake Huumonjärvi (P. Marttila-Tornio, pers. comm., 2010). Temperature of surface water in the lake was $18^{\circ} \mathrm{C}$ in August 2008 when the snails were obtained.

The sampled snails $(n=61)$ were all reproductiveage adults (shell height $>40 \mathrm{~mm}$ ). After the sampling the snails were placed in a large bucket of water from Lake Huumonjärvi and transported in the laboratory at the University of Eastern Finland, Joensuu campus, Finland. There the snails were acclimated to non-chlorinated tap water $\left(17-18^{\circ} \mathrm{C}\right.$, range), commercial pelleted fish food (BioMar ${ }^{\circledR}$, Aqualife, Denmark) and artificial feeding schedule (twice per day, in the beginning of the illuminated and dark periods). The snails were also fed lettuce ad libitum. The snails adapted well to the artificial food. Actually, they preferred fish food to lettuce. To verify whether the snails were parasitized or unparasitized they were placed singly in transparent $0.5 \mathrm{~L}$ plastic beakers of tap water overnight at $20^{\circ} \mathrm{C}$ (see Voutilainen et al., 2009). In the next morning, $10 \mathrm{~mL}$ water samples pipetted from the beakers were examined microscopically (stereomicroscope Leica ${ }^{\circledR}$ MZ95, Leica Microsystems, Heerbrugg, Switzerland) for the presence of parasite cercariae emerged from the snails. Cercariae were identified on the basis of morphology and size (Bock, 1984; Niewiadomska, 1986; Niewiadomska et al., 1997; Voutilainen and Taskinen, 2009).

Then, six snails parasitized by $D$. pseudospathaceum (Fig. 1), six snails parasitized by P. elegans (Fig. 1) and six unparasitized snails were randomly chosen for the experiments. Those 18 snails were individually marked by gluing (Loctite $^{\circledR}$, Loctite Corp., Göteborg, Sweden) three plastic tags of different colours on the shell of each snail. The marked snails were placed in a $165 \mathrm{~L}$ plastic experiment aquarium (55 cm (width) $\times 75 \mathrm{~cm} \quad$ (length) $\times 40 \mathrm{~cm}$ (height)) (Fig. 2) of tap water at $17-18^{\circ} \mathrm{C}$ (range) under bright diffuse sunlight through large windows and a constant photoperiod (12L:12D). The nights are quite short in Finland in August (about $8 \mathrm{~h}$ including dusk and dawn) and, therefore, curtains were drawn across the windows to shelter the experiment aquarium from sunlight during the dark periods. A non-transparent vertical plastic plate divided the experiment aquarium into two $82.5 \mathrm{~L}$ sections (Fig. 2). The snails were placed in the left section and the food (commercial pelleted fish food) for the snails was rationed out in the right section at the beginning of the illuminated and dark periods i.e. twice per day. Experimental snails could access the food through a $5 \mathrm{~cm} \times 5 \mathrm{~cm}$ opening in the lower edge of the middle plate (Fig. 2).

The experiments I, II, III and IV (Table 1) were serially carried out after the snails were acclimated to the aquarium conditions and artificial feeding schedule for several 

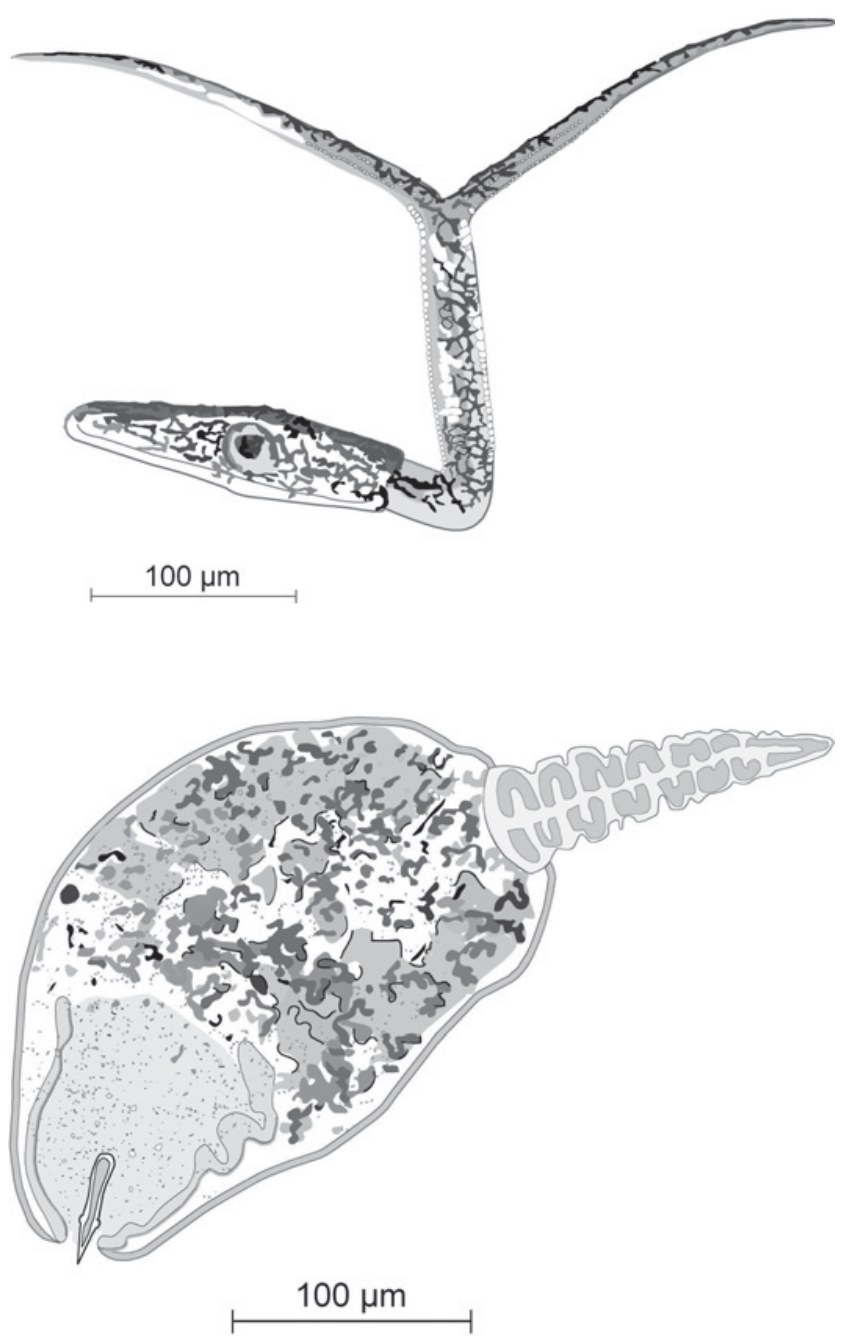

Fig. 1. Schematic two-dimensional drawings representing a cercaria of Diplostomum pseudospathaceum (upper figure) and that of Plagiorchis elegans (lower figure).

days in September 2008. Prior to each experiment the snails were fasted for two days. In the experiments, the number of the snails that were feeding the food pellets in the right section of the experiment aquarium was counted twice $24 \mathrm{~h}^{-1}$; first time in the morning after the $12 \mathrm{~h}$ period of darkness and second time in the evening after the $12 \mathrm{~h}$ period of illumination. After the counting, all snails were returned to the left section of the aquarium, where no food was available. Each experiment lasted $48 \mathrm{~h}$ and thus the number of snails in the right section of the aquarium was counted four times per experiment. The experiments were started all at the same time in the evening and the first observation of snails was performed always in the next morning after the darkness.

The experiments I and III were controls for the experiments II and IV, respectively, and they were carried out in the absence of predators (Table 1). In the other two experiments a facultative nocturnal (crayfish, experiment II) or an efficient diurnal molluscivore (crucian carp, experiment IV) was placed in the upper right section of the experiment aquarium (Fig. 2). A horizontal plastic plate

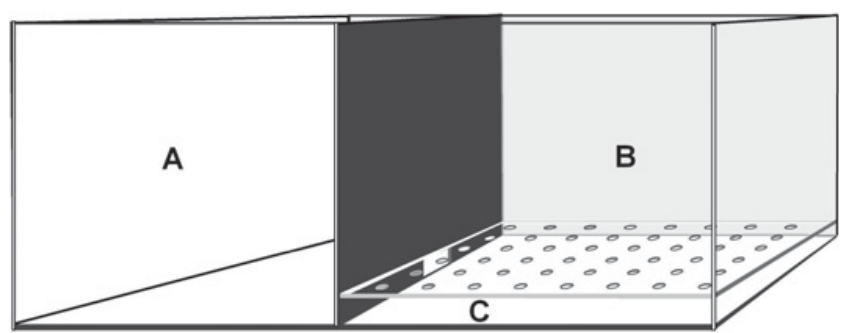

Fig. 2. Schematic representation of the $165 \mathrm{~L}$ experimental plastic aquarium. A non-transparent vertical plate divided the aquarium into two sections (A and B). Snails were initially placed in the section A and could access the food rationed out at regular $12 \mathrm{~h}$ intervals in the subsection $\mathrm{C}$, obtained by inserting a horizontal plate in the section $\mathrm{B}$ that housed the predators when present. The horizontal plate was transparent and perforated to allow visual and chemical predator awareness. Details can be found in the text.

fixed to the walls of the aquarium at a height of $5 \mathrm{~cm}$ from the bottom of the aquarium divided the right section of the aquarium into two subsections so that physical contact between the predator and the snails was prevented (Fig. 2). The horizontal plate was transparent and perforated (40 punctures, $\varnothing 10 \mathrm{~mm}$ ) so that the predator and the snails were able to see and smell each other. The experiment aquarium was cleaned and the water in the aquarium was changed every $48 \mathrm{~h}$ i.e. after each fasting period and experiment. The chosen predators (crayfish and crucian carp) have different kind of technique in dealing with snail prey. Crayfish use their claws to crush the snail's shell (Nyström and Perez, 1998) whereas crucian carps crush the shell in the mouth. However, as both predator individuals used in the experiments were large, they exerted a roughly equivalent predation pressure on the snails. Length of the crayfish was $12 \mathrm{~cm}$, excluding the chelipeds i.e. the main claws. Total length of the crucian carp was $c .30 \mathrm{~cm}$ and its fresh mass was $c .500 \mathrm{~g}$.

After the last experiment (IV), the snails were weighed for whole mass and crushed. The tissue of the crushed snails was examined microscopically to verify the infection status of the snails (parasitized by D. pseudospathaceum, parasitized by $P$. elegans or unparasitized). The intensity of the parasite infection was scored on the basis of the affected visceral area as follows: $0=$ no parasites, $1=$ the visceral mass looked like normal but was infected by a few parasite larvae, $2=$ less than $\frac{1}{3}$ of the visceral mass was invaded by parasites, $3=\frac{1}{3}-\frac{2}{3}$ of the visceral mass was invaded by parasites and $4=$ more than $\frac{2}{3}$ of the visceral mass was invaded by parasites.

A univariate analysis of covariance (ANCOVA) was used to test for differences in the snails' foraging activity. The light condition (diffuse sunlight or darkness), the snail's infection status (unparasitized, parasitized by $P$. elegans or parasitized by D. pseudospathaceum) and the level of predation risk (predators absent, crayfish present or fish present) were used as fixed factors in the ANCOVA. The number of feeding events per snail individual per experiment was used as a dependent variable 
Table 1. Summary of the experiments conducted to find out interaction effects of light condition, parasitism and predation risk on foraging activity in the great pond snail Lymnaea stagnalis.

\begin{tabular}{|c|c|c|c|c|c|c|c|c|}
\hline & Fast & Experiment I & Fast & Experiment II & Fast & Experiment III & Fast & Experiment IV \\
\hline Duration & $48 \mathrm{~h}$ & $\begin{array}{c}48 \mathrm{~h} \\
3^{\text {rd }} \text { and } 4^{\text {th }} \\
\text { days }\end{array}$ & $48 \mathrm{~h}$ & $\begin{array}{c}48 \mathrm{~h} \\
7^{\text {th }} \text { and } 8^{\text {th }} \\
\text { days }\end{array}$ & $48 \mathrm{~h}$ & $\begin{array}{c}48 \mathrm{~h} \\
11^{\text {th }} \text { and } 12^{\text {th }} \\
\text { days }\end{array}$ & $48 \mathrm{~h}$ & $\begin{array}{c}48 \mathrm{~h} \\
15^{\text {th }} \text { and } 16^{\text {th }} \\
\text { days }\end{array}$ \\
\hline Photoperiod & $12 \mathrm{D}: 12 \mathrm{~L}$ & 12D:12L & $12 \mathrm{D}: 12 \mathrm{~L}$ & $12 \mathrm{D}: 12 \mathrm{~L}$ & 12D:12L & $12 \mathrm{D}: 12 \mathrm{~L}$ & $12 \mathrm{D}: 12 \mathrm{~L}$ & $12 \mathrm{D}: 12 \mathrm{~L}$ \\
\hline Feeding & No & $\begin{array}{l}\text { Twice } \\
\text { per day }\end{array}$ & No & $\begin{array}{l}\text { Twice } \\
\text { per day }\end{array}$ & No & $\begin{array}{l}\text { Twice } \\
\text { per day }\end{array}$ & No & $\begin{array}{l}\text { Twice } \\
\text { per day }\end{array}$ \\
\hline $\begin{array}{l}\text { Predator } \\
\text { presence }\end{array}$ & No & No & No & $\begin{array}{c}\text { Yes } \\
\text { (a crayfish) }\end{array}$ & No & No & No & $\begin{array}{l}\text { Yes } \\
\text { (a fish) }\end{array}$ \\
\hline
\end{tabular}

Table 2. Number of feeding events per snail (Lymnaea stagnalis) individual per experiment in diffuse daylight and darkness. The snails were either unparasitized or parasitized by the trematodes Plagiorchis elegans or Diplostomum pseudospathaceum and stressed by the presence of a predator except in the control experiments. A detailed description of the statistical data analyses can be found in the text and Table 3.

\begin{tabular}{lccc}
\hline Light conditions & Infection status & Predator presence & $\begin{array}{c}\text { Number of feeding events per } \\
\text { snail individual (mean } \pm \text { SD) }\end{array}$ \\
\hline Light & No parasites & No predator & $1.4 \pm 0.5$ \\
& Plagiorchis & No predator & $1.5 \pm 0.4$ \\
& Diplostomum & No predator & $0.4 \pm 0.6$ \\
Light & No parasites & Crayfish & $1.7 \pm 0.5$ \\
& Plagiorchis & Crayfish & $1.5 \pm 0.8$ \\
& Diplostomum & Crayfish & $1.3 \pm 0.8$ \\
Light & No parasites & Fish & $1.7 \pm 0.5$ \\
& Plagiorchis & Fish & $1.5 \pm 0.5$ \\
& Diplostomum & Fish & $2.0 \pm 0.0$ \\
Darkness & No parasites & No predator & $0.8 \pm 0.7$ \\
& Plagiorchis & No predator & $0.9 \pm 0.5$ \\
Diplostomum & No predator & $0.6 \pm 0.6$ \\
& & & $1.2 \pm 0.8$ \\
Darkness & No parasites & Crayfish & $0.8 \pm 0.8$ \\
& Plagiorchis & Crayfish & $0.2 \pm 0.4$ \\
& Diplostomum & Crayfish & $1.2 \pm 0.8$ \\
& & & $0.8 \pm 0.8$ \\
& No parasites & Fish & $1.0 \pm 0.6$ \\
\hline
\end{tabular}

in the ANCOVA. The ANCOVA was followed by Tukey's HSD multiple comparison tests for the snails' parasite status (three groups) and the level of predation risk (three groups) and a paired samples $t$-test for the light conditions (two groups). For the analyses the data was pooled over the control experiments (I and III) and the number of feeding events per snail individual was expressed in events per experiment i.e. the total number of feeding events per snail in the control experiments was divided by two.

\section{Results}

All three factors (light condition, parasite status and predator status) affected the number of feeding events per snail individual per experiment (Tables 2 and 3). The snails made a greater number of feedings events per individual under bright diffuse daylight than in the dark (paired samples $t$-test, $t_{53}=4.777, p<0.0005$ ). The snails parasitized by $D$. pseudospathaceum made fewer feeding events per individual than their unparasitized conspecifics (Tukey's HSD, $p=0.019$ ). Moreover, the snail's parasite status and the level of predation risk had an interaction effect on the number of feeding events per snail individual (Table 3) so that especially the snails parasitized by D. pseudospathaceum made more feeding events in the presence of the fish than in the absence of predators (Tukey's HSD, $p=0.014$ ) (Table 2). There was no difference in the number of feeding events per snail between the unparasitized snails and the snails parasitized 
Table 3. ANCOVA statistics for the number of feeding events per snail (Lymnaea stagnalis) individual in two different light conditions (diffuse daylight and darkness) in the absence and presence of predators (crayfish or fish). The snails were either unparasitized or parasitized by the trematodes Plagiorchis elegans or Diplostomum pseudospathaceum. Statistically significant effects on the snails' feeding $(p<0.05)$ have been indicated with asterisks $(*)$.

\begin{tabular}{|c|c|c|c|c|c|}
\hline Source of variation & Sum of squares & $\overline{d f}$ & Mean square & $F$ & $p$ \\
\hline Light condition & 10.083 & 1 & 10.083 & 26.432 & $<0.0005^{*}$ \\
\hline Parasite status & 3.014 & 2 & 1.507 & 3.950 & $0.023^{*}$ \\
\hline Predator presence & 3.167 & 2 & 1.583 & 4.150 & $0.019 *$ \\
\hline Interaction (light × parasite) & 0.097 & 2 & 0.049 & 0.127 & 0.881 \\
\hline Interaction (light $\times$ predator $)$ & 1.056 & 2 & 0.528 & 1.383 & 0.256 \\
\hline Interaction (parasite $\times$ predator) & 4.028 & 4 & 1.007 & 2.640 & $0.039 *$ \\
\hline Interaction $($ light $\times$ parasite $\times$ predator $)$ & 2.139 & 4 & 0.535 & 1.402 & 0.240 \\
\hline
\end{tabular}

by $P$. elegans (Tukey's HSD, $p=0.608$ ) or between the snails parasitized by $D$. pseudospathaceum and the snails parasitized by $P$. elegans (Tukey's HSD, $p=0.171$ ). The number of feeding events per snail individual observed in the absence of predators did not differ from that observed in the presence of a crayfish (Tukey's HSD, $p=0.489$ ) and the number of feeding events per snail in the presence of a crayfish did not differ from that in the presence of a fish (Tukey's HSD, $p=0.204$ ).

The intensity of the parasite infection did not differ between the snails infected with $D$. pseudospathaceum (mean intensity of the infection was 2.8; $\mathrm{Q}_{1}$ was 1.0 , median was 2.0 and $\mathrm{Q}_{3}$ was 4.0 ) and the snails infected with P. elegans $\left(\right.$ mean $=2.3 ; \mathrm{Q}_{1}=1.8$, median $\left.=2.0, \mathrm{Q}_{3}=3.3\right)$ (MannWhitney U-test, $Z=-0.663, p=0.589)$. The intensity of the infection did not correlate with the number of feeding events per snail individual per experiment in the snails that were parasitized by $D$. pseudospathaceum (Spearman's rank correlation $r_{\mathrm{s}}=-0.433, n=6, p=0.391$ ) or in the snails that were parasitized by $P$. elegans $\left(r_{\mathrm{s}}=-0.375\right.$, $n=6, p=0.464)$. Whole snail mass $(6.8 \pm 0.2 \mathrm{~g}$, mean \pm $\mathrm{SE}$ ) did not differ between the three groups (parasitized by $D$. pseudospathaceum, parasitized by $P$. elegans and unparasitized) (one-way analysis of variance, $F_{2,15}=2.57$, $p=0.110)$.

\section{Discussion}

The observed altered foraging activity pattern in the snails L. stagnalis parasitized by D. pseudospathaceum can be explained in at least the following ways. (1) The snails foraged more actively in the presence of a fish predator than in the absence of predators because the snails' foraging behaviour was manipulated by the parasite (confirmation of the first hypothesis of the study). Cercariae of D. pseudospathaceum develop in sporocysts located inside the snail and emerge from the snail into the water when the sporocysts erupt. The amount of released cercariae greatly varies within and between days, although more cercariae on an average are released during daytime and especially in the morning than during the night (Karvonen et al., 2004). Life span of the cercariae is about $24 \mathrm{~h}$ but their infectivity in fish (second intermediate hosts for the parasite) starts to decrease already after the first hours in the water (Karvonen et al., 2003). Consequently, the cercariae of $D$. pseudospathaceum get benefit from being released from the snail in close vicinity to their next hosts i.e. fish - especially as the cercariae are not able to actively swim towards the fish. Whether the increased foraging activity of the snails parasitized by $D$. pseudospathaceum in the presence of fish is true parasite manipulation or just a by-product of the infection, likelihood of the parasite's transmission to its second intermediate host increases, if the parasitized snails "seek" the fish. The cercariae of D. pseudospathaceum infect the fish by penetrating its skin (Niewiadomska, 1996) and, therefore, they have no need of being eaten by the fish. Host manipulation by parasites in snail-trematode interactions have been verified in the relationship between the New Zealand mud snail Potamopyrgus antipodarum (Gray) and the trematode Microphallus sp. (Digenea: Microphallidae) (Levri, 1999; Levri et al., 2007). The behavioural changes in $P$. antipodarum caused by Microphallus sp. are specific to this particular host-parasite relationship. Potamopyrgus antipodarum parasitized by other trematodes than Microphallus sp. behave similarly to their unparasitized conspecifics (Levri et al., 2007).

(2) The snails parasitized by D. pseudospathaceum made fewer feeding events per individual i.e. they were less hungry than their unparasitized conspecifics because the demand for energy of the snails was lowered as a result of the infection. In general, trematode parasitism lowers the metabolic rate of the parasitized L. stagnalis (Duerr, 1967). However, the effect of parasitism on the metabolic rate of the snails is highly variable and depends on the parasite's type. The metabolic rate of L. stagnalis infected with digenetic trematodes that shed so-called Strigea cercariae (like D. pseudospathaceum does) is affected more than that of L. stagnalis infected with trematodes that shed xiphidiocercariae (like P. elegans does) (Duerr, 1967).

The snails display avoidance behaviour less actively, when their shell is large and strong enough to make them invulnerable to the existent predation (Alexander and Covich, 1991b; Covich et al., 1994). In the present study, although all the snails were large adults, most of the snails that stayed at the left side of the experiment aquarium, where no food or predators were present, crawled out of the water especially during the dark periods and when the crayfish was present in the right side of the aquarium 
(partial confirmation of the second hypothesis of the study). The behaviour can be considered a specific type of predator avoidance induced by the cues from crustacean predators (Alexander and Covich, 1991a; McCarthy and Fisher, 2000). Crawling out of the water in the presence of crayfish predators is especially typical for lymnaeid snails (Covich et al., 1994). On the other hand, crawling above the water and voluntary returning back into the water shortly thereafter is also typical for unstressed pulmonate snails, especially after feeding (Lombardo et al., 2010). Furthermore, it is possible that the snails crawl out of the aquarium to seek food, if they are hungry. In this study, however, food was available in excess during the experiments and the snails' feeding activity in the presence of the crayfish did not differ from that in the absence of predators. Actually, the snails did not try to escape from the aquarium but they just crawled out of the water and stayed above the surface until they were manually returned back into the water. I venture, consequently, to propose that the snails responded directly to cues from the crayfish and the ultimate cause of the snails' altered behaviour was the risk of predation.

Why then did the snails not try to avoid the fish predator? That is an interesting question because predation pressure exerted on the snails by a large crucian carp should not differ from the pressure exerted by a large crayfish. The snails were obtained from Lake Huumonjärvi where both crustacean and fish predators of aquatic snails are present. However, fish fauna of the lake does not include the crucian carp but other potential cyprinid predators of the snails, such as large roach. It may be possible, or even probable, that the snails L. stagnalis obtained from Lake Huumonjärvi, which had no previous contact to crucian carps, were not able to identify the species as a predator (see Keppel and Scrosati, 2004) (probable solution to the third hypothesis of the study). On the other hand, also the possibility that the snails responded to cues from the crucian carp in ways that were not noticed, e.g. withdrawing the entire body into the shell or trying to hide at the bottom of the aquarium, must keep in mind.

As the experimental snails were fasted for $48 \mathrm{~h}$ prior to each experiment (I, II, III and IV), I acknowledge that the snails might have been hungrier during the first observation period i.e. the first $12 \mathrm{~h}$ from the beginning of the dark period than during the last three periods in each experiment (see Ter Maat et al., 2007). However, although the caution have to be noted in this context, the possible bias in snail behaviour caused by the difference in hunger levels was equal in every experiment and, consequently, it did not seriously affect the result. The snails L. stagnalis, in the present study, had an evident circadian foraging rhythm. They preferred diurnal foraging both in the absence and presence of the predators. This is in accordance with the findings concerning the general diel activity cycles of unstressed freshwater gastropods (Lombardo et al., 2010).

To conclude, both the unstressed and stressed snails L. stagnalis were mainly diurnal feeders, although the biotic stressors (predation risk and parasitism) had evident interaction effects on the foraging activity in the snails.
The individuals parasitized by $D$. pseudospathaceum foraged less actively than the unparasitized individuals except in the presence of the fish predator. Some of the unparasitized and parasitized snails tried to avoid the crayfish predator by crawling out of the water. The results suggest that $D$. pseudospathaceum may be capable of manipulating the behaviour of its first intermediate snail hosts to enhance its success of transmission to the parasite's second intermediate fish hosts. As the snails parasitized by $P$. elegans had a similar circadian feeding rhythm to their unparasitized conspecifics, both in the absence and presence of the predators, the altered foraging behaviour in the snails parasitized by $D$. pseudospathaceum was not a generalized response to parasitism. However, I want to stress the point that the proposed host manipulation as a parasites' transmission strategy in the relationship between $L$. stagnalis and $D$. pseudospathaceum needs to be studied more precisely in the future. The present findings revealed that the effects of biotic factors such as predation risk and parasitism on the biological rhythms and behaviour of snails (and other animals as well) may be interactive and highly specialized rather than generalized.

Acknowledgements. I thank P. Väisänen for her help in carrying out the experiments, T. Ikonen for her help in snail sampling, K. Kyyrönen for drawing Figures 1 and 2, H. Huuskonen for supplying the crayfish, M. Vornanen for supplying the crucian carp and two anonymous reviewers for their valuable comments on the manuscript. The study has been financially supported by the Graduate School in Biological Interactions with a grant to the author.

\section{References}

Alexander J.E. Jr. and Covich A.P., 1991a. Predator avoidance by the freshwater snail Physella virgata in response to the crayfish Procambarus simulans. Oecologia, 87, 435442.

Alexander J.E. Jr. and Covich A.P., 1991b. Predation risk and avoidance behavior in two freshwater snails. Biol. Bull., 180, 387-393.

Ballabeni P., 1995. Parasite-induced gigantism in a snail: a host adaptation? Funct. Ecol., 9, 887-893.

Bock D., 1984. The life cycle of Plagiorchis spec. 1, a species of the Plagiorchis elegans group (Trematoda, Plagiorchiidae). Z. Parasitenk., 70, 359-373.

Covich A.P., Crowl T.A., Alexander J.E. Jr. and Vaughn C.C., 1994. Predator-avoidance responses in freshwater decapodgastropod interactions mediated by chemical stimuli. J. N. Am. Benthol. Soc., 13, 283-290.

Duerr F.G., 1967. Changes in the size-metabolic rate relationship of Lymnaea stagnalis appressa Say produced by digenetic trematode parasitism. Comp. Biochem. Physiol., 20, 391-398.

Karvonen A., Paukku S., Valtonen E.T. and Hudson P.J., 2003. Transmission, infectivity and survival of Diplostomum spathaceum cercariae. Parasitology, 127, 217-224. 
Karvonen A., Kirsi S., Hudson P.J. and Valtonen E.T., 2004. Patterns of cercarial production from Diplostomum spathaceum: terminal investment or bet hedging? Parasitology, 129, 87-92.

Keppel E. and Scrosati R., 2004. Chemically mediated avoidance of Hemigrapsus nudus (Crustacea) by Littorina scutulata (Gastropoda): effects of species coexistence and variable cues. Anim. Behav., 68, 915-920.

Levri E.P., 1999. Parasite-induced change in host behavior of a freshwater snail: parasitic manipulation or byproduct of infection? Behav. Ecol., 10, 234-241.

Levri E.P. and Fisher L.M., 2000. The effect of a trematode parasite (Microphallus sp.) on the response of the freshwater snail Potamopyrgus antipodarum to light and gravity. Behaviour, 137, 1141-1151.

Levri E.P., Lunnen S.J., Itle C.T., Mosquea L., Kinkade B.V., Martin T.G. and DeLisser M.A., 2007. Parasite-induced alteration of diurnal rhythms in a freshwater snail. J. Parasitol., 93, 231-237.

Lombardo P., Miccoli F.P., Giustini M. and Cicolani B., 2010. Diel activity cycles of freshwater gastropods under natural light: patterns and ecological implications. Ann. Limnol. - Int. J. Lim., 46, 29-40.

McCarthy T.M. and Fisher W.A., 2000. Multiple predatoravoidance behaviours of the freshwater snail Physella heterostropha pomila: responses vary with risk. Freshwater Biol., 44, 387-397.

Niewiadomska K., 1986. Verification of the life-cycles of Diplostomum spathaceum (Rudolphi, 1819) and D. pseudospathaceum Niewiadomska, 1984 (Trematoda, Diplostomidae). Syst. Parasitol., 8, 23-31.

Niewiadomska K., 1996. The genus Diplostomum - taxonomy, morphology and biology. Acta Parasitol., 41, 55-66.

Niewiadomska K., Valtonen E.T. and Siddall R., 1997. Cercariae from Lymnaea stagnalis in lake Kuuhankavesi (central Finland). Acta Parasitol., 42, 132-137.

Nyström P. and Perez J.R., 1998. Crayfish predation on the common pond snail (Lymnaea stagnalis): the effect of habitat complexity and snail size on foraging efficiency. Hydrobiologia, 368, 201-208.

Seppälä O., Karvonen A. and Valtonen E.T., 2004. Parasiteinduced change in host behaviour and susceptibility to predation in an eye fluke-fish interaction. Anim. Behav., 68, 257-263.
Seppälä O., Karvonen A. and Valtonen E.T., 2005. Manipulation of fish host by eye flukes in relation to cataract formation and parasite infectivity. Anim. Behav., 70, 889894.

Sih A. and McCarthy T.M., 2002. Prey responses to pulses of risk and safety: testing the risk allocation hypothesis. Anim. Behav., 63, 437-443.

Ter Maat A., Zonneveld C., de Visser J.A.G.M., Jansen R.F., Montagne-Wajer K. and Koene J.M., 2007. Food intake, growth, and reproduction as affected by day length and food availability in the pond snail Lymnaea stagnalis. Amer. Malac. Bull., 23, 113-120.

Turner A.M., 1996. Freshwater snails alter habitat use in response to predation. Anim. Behav., 51, 747-756.

Turner A.M., Fetterolf S.A. and Bernot R.J., 1999. Predator identity and consumer behavior: differential effects of fish and crayfish on the habitat use of a freshwater snail. Oecologia, 118, 242-247.

Voutilainen A. and Taskinen J., 2009. Infectivity of Diplostomum spp. in Arctic charr: Aspects of exposure duration and cercariae morphology. J. Parasitol., 95, 527-531.

Voutilainen A., van Ooik T., Puurtinen M., Kortet R. and Taskinen J., 2009. Relationship between prevalence of trematode parasite Diplostomum sp. and population density of its snail host Lymnaea stagnalis in lakes and ponds in Finland. Aquat. Ecol., 43, 351-357.

Zakikhani M. and Rau M.E., 1998. Effects of Plagiorchis elegans (Digenea: Plagiorchiidae) infection on the reproduction of Biomphalaria glabrata (Pulmonata: Planorbidae). J. Parasitol., 84, 927-930.

Zakikhani M. and Rau M.E., 1999. Plagiorchis elegans (Digenea: Plagiorchiidae) infections in Stagnicola elodes (Pulmonata: Lymnaeidae): host susceptibility, growth, reproduction, mortality, and cercarial production. J. Parasitol., 85, 454 463.

Zakikhani M., Smith J.M. and Rau M.E., 2003. Effects of Plagiorchis elegans (Digenea: Plagiorchiidae) infection of Biomphalaria glabrata (Pulmonata: Planorbidae) on a challenge infection with Schistosoma mansoni (Digenea: Schistosomatidae). J. Parasitol., 89, 70-75.

Żbikowska E. and Żbikowski J., 2005. Differences in shell shape of naturally infected Lymnaea stagnalis (L.) individuals as the effect of the activity of digenetic trematode larvae. J. Parasitol., 91, 1046-1051. 